\title{
O Blog como Ferramenta de Apoio às Funções do NTE- Regional: Gestão, Acompanhamento e Orientação do Uso das TDIC na Escola
}

\author{
Dirce Cristiane Camilotti ${ }^{1}$ \\ ${ }^{1}$ Secretaria de Estado de Educação - Mato Grosso do Sul (SED/MS) \\ Núcleo de Tecnologia Educacional Regional (NTE-Regional) \\ dcamilotti@gmail.com
}

\begin{abstract}
This paper analyzes the use of the blog as support functions of NTERegional tool. Through a qualitative analysis using observation and questionnaire was made the description and evaluation of the blog. The analysis showed that it was necessary to create multiple blogs interconnected to support the core functions and that the systematic and hierarchical organization assigns functionality to the blog of NTE-Regional in a hypertext system. The data obtained in the evaluation demonstrated that the design, presentation and form are appropriate, the material is reliable and objective, but there is need for greater outreach to encourage interaction and ownership of the blog in the pedagogical practice of teachers and administrators.
\end{abstract}

Resumo. Este trabalho analisa o uso do blog como ferramenta de apoio às funções do NTE-Regional. Por meio de análise qualitativa utilizando observação e questionário foi realizada a descrição e avaliação do blog. A análise demonstrou que foi necessária a criação de vários blogs interligados para apoiar as funções do núcleo e que a organização sistematizada e hierárquica atribui funcionalidade ao blog do NTE-Regional num sistema de hipertexto. Os dados obtidos na avaliação demonstraram que o design, apresentação e forma são adequados, o material é confiável e objetivo, mas há necessidade de maior divulgação para estimular a interação e apropriação do blog na prática pedagógica de professores e gestores.

\section{Introdução}

O blog é um dos recursos encontrados na Web 2.0 que pode contribuir para a melhoria da prática pedagógica. Sua inserção no âmbito escolar requer uma nova postura docente e discente diferente do ensino tradicional, no sentido de promover um ensino contextualizado e colaborativo. Faz-se necessário que o professor reflita sobre essa nova realidade e construa novas formas de ações, a fim de utilizar esse recurso como meio de inovar o processo de ensino-aprendizagem e ampliar a relação entre professores e alunos e alunos-alunos, abrindo espaço para a autoria e co-autoria e não somente realizar atividades propostas [Prado 2010; Araújo, 2009].

Nesse cenário é relevante o papel do NTE (Núcleo de Tecnologia Educacional) junto à escola e principalmente aos professores, incentivando-os no planejamento de suas atividades e ofertando subsídios para integração das novas tecnologias em sua prática docente, principalmente quanto ao uso de blogs. 
Apoiado no conceito de interação, fundamentado pela teoria sócio-interacionista de Vygotsky, o objetivo desse trabalho foi analisar como o Núcleo de Tecnologia Educacional Regional (NTE-Regional) da Rede Estadual de Ensino de Mato Grosso do Sul utiliza a ferramenta "Blog" no desempenho de suas funções de forma a construir um espaço de construção coletiva do conhecimento, por meio de um relato de experiência utilizando observação direta e aplicação de questionário. Trata-se de um relato de experiência, a partir do uso do blog como subsídio para a realização das ações do NTERegional. Embora o uso do blog como recurso pedagógico seja bastante comum, sua utilização como ferramenta de apoio às funções dos NTEs da Rede Estadual de Ensino de Mato Grosso do Sul de forma sistematizada e de acordo com a legislação vigente é pouco comum, sobretudo no acompanhamento e orientação às escolas.

Assim, esse trabalho é relevante por permitir a socialização da forma de organização e utilização do blog do NTE-Regional, apresentando o blog como uma ferramenta em potencial para gestão democrática e colaborativa das escolas pelos NTEs, podendo ser um referencial para outros núcleos que queiram fazer uso da ferramenta.

\subsection{O Blog como ferramenta educacional}

Por ser uma ferramenta interativa, os blogs oferecem grande potencial para serem utilizados como recursos didáticos e de gestão, sendo indispensáveis a educadores e gestores que queiram estabelecer uma forma de comunicação através de um ambiente de motivação, discussão, criação e divulgação do conhecimento. Possibilitam visibilidade a assuntos relevantes para a comunidade, trabalho colaborativo, expressão individual, formação de redes e ambiente de suporte para projetos educacionais [Lévy 2005; Pontes e Filho 2011].

Os blogs na educação podem ser utilizados para apresentar projetos desenvolvidos na escola; criar jornais online; divulgar atividades, estudos e produções realizados por alunos e professores; oferecer apoio a um eixo de trabalho e/ou uma disciplina; preparar para encontros educacionais entre diferentes profissionais; aguçar a curiosidade e exploração dos recursos tecnológicos; desenvolver habilidades e competências interdisciplinares de forma integrada ao currículo e ampliar as habilidades cognitivas na área de criação [Araújo, 2009].

Considerando as ideias de Vygostky (2008), pode-se caracterizar o uso das ferramentas disponíveis no blog como um processo onipresente na Zona de Desenvolvimento Proximal, capaz de promover a interação, cooperação, comunicação e motivação a fim de diversificar e potencializar as relações entre sujeitos-sujeitos e sujeitos-tecnologias, colaborando para a estruturação do conhecimento coletivo.

Os NTEs podem beneficiar-se das diversas possibilidades de uso do blog como um potencial viabilizador da relação interpessoal com o objetivo de estimular a aprendizagem colaborativa e fomentar a construção do conhecimento, a partir de um instrumento atual e utilizado como forma de expressão.

\subsection{O NTE-Regional e a criação do Blog}

O NTE Regional tem a função de acompanhar, orientar e avaliar o uso das TDIC (Tecnologias Digitais da Informação e Comunicação) nas suas escolas jurisdicionadas, por meio dos Professores Gerenciadores de Tecnologias Educacionais - PROGETECs [Mato Grosso do Sul, 2011]. Oferece apoio aos professores em suas atividades pedagógicas, tendo como referenciais teorias que consideram o processo pedagógico em sua totalidade de relações e os componentes constitutivos deste processo como 
elementos que influenciam e são influenciados na prática educativa, tomando o cuidado de realizar constante autoavaliação, objetivando manter a coerência do processo.

O referido núcleo subsidia o uso das TDIC nas escolas de dez municípios da rede pública Estadual e Municipal: Bandeirantes, Camapuã, Corguinho, Jaraguari, Nova Alvorada do Sul, Ribas do Rio Pardo, Rio Negro, Rochedo, Sidrolândia e Terenos. Possibilita o acompanhamento pedagógico e a realização de cursos de formação continuada em 23 escolas. Compõe junto com outros onze NTEs de Mato Grosso do Sul o local na Secretaria de Educação de Mato Grosso do Sul que tem o papel de oferecer subsídios para o gerenciamento das tecnologias na escola e a realização de ações pedagógicas que tragam efetivamente melhoria para a qualidade do ensino. É através dele que professores e gestores têm acesso às novas tecnologias e metodologias e mantêm contato com outras instituições que utilizam os recursos tecnológicos em práticas pedagógicas diferenciadas.

Para o NTE desempenhar suas funções é necessário, além das visitas e uso de ferramentas síncronas, um local de interação constante que privilegie não apenas a comunicação entre equipe do NTE e Escola, mas também que seja um espaço de orientação, divulgação e compartilhamento de experiências num ambiente virtual. Diante dessa necessidade a equipe do NTE-Regional optou pela criação de um blog organizado de acordo com as funções elencadas na Resolução/SED/MS 2791 e posteriormente na Resolução/SED/MS 2491 [Mato Grosso do Sul, 2011].

A decisão pelo uso do blog se deu pela sua funcionalidade, já que ele se diferencia de outras ferramentas pela sua dinamicidade e pela facilidade de acesso e de atualização. Além disso, em relação ao site tradicional sua manutenção e edição são mais simples e permite maior interação e discussões mais centradas a partir dos diferentes posts. O uso do blog pelo NTE configura-se assim, um meio de comunicação que permite maior interação, coordenação, cooperação e possibilidade de redefinição de conteúdos e práticas através da divulgação de conteúdos relacionados à gestão das tecnologias e atividades, reflexão do trabalho individual por meio de ação coletiva e visualização do que está sendo realizado em todas as escolas.

\section{Metodologia}

A fim de analisar o uso do blog como apoio às funções do NTE-Regional nas escolas optou-se por uma pesquisa qualitativa. As informações foram coletadas diretamente pelo investigador por meio da exploração do blog da instituição sem ter contato inicial com os gestores e professores que acessam e utilizam o ambiente. A partir dessa exploração foi realizada a descrição de cada espaço do blog, considerando "para que e como" é utilizado, e a relação do seu uso com as funções desempenhadas pelo NTERegional.

Além da observação foi utilizado como instrumento de coleta de dados um questionário online para avaliar a implantação do blog. O questionário foi composto por 15 questões de múltipla escolha e duas questões abertas, totalizando 17 questões. As perguntas de múltipla escolha foram divididas em quatro blocos que avaliaram os seguintes itens relativos à estrutura e uso do blog: a) Design, apresentação e forma; b) Estética e legibilidade; c) Confiabilidade e objetividade; d) Interação e relação com a prática docente. As duas questões abertas versavam sobre a opinião dos respondentes quanto às vantagens do uso do "Blog NTE-Regional" e as sugestões para melhorá-lo.

A análise dos dados do questionário foi efetuada no decorrer de todo processo investigativo e apoiada na metodologia de Bardin (1977). Foram utilizados três pólos 
cronológicos para a análise de conteúdo, organizados como: pré-análise, exploração do material e interpretação. Na pré-análise houve o contato inicial com os questionários, visualização do conjunto de dados e o planejamento da melhor maneira de organizá-los. Foi realizada uma leitura flutuante dos dados, constatando um contato inicial com os registros dos questionários a fim de operacionalizar as ideias iniciais.

A segunda fase constituiu-se na definição dos sistemas de categoria, de codificação e a identificação das unidades de registro, que permitiram atingir uma representação das características pertinentes ao conteúdo e referencial. Foi feito um estudo mais aprofundado do material disponível e trabalhadas as quatro categorias já construídas no questionário. As questões abertas foram analisadas pelo método de análise de conteúdo [Bardin 1977], sendo examinadas todas as respostas e separadas as categorias. Por tratar-se de questões que indagavam sobre as vantagens e sugestões para melhoria do blog, cada pergunta poderia ter mais de uma resposta, o que permitiu a escolha de mais de uma categoria por respondente.

$\mathrm{Na}$ terceira fase foi realizado o tratamento dos dados e interpretação a partir da categoria determinadas na fase anterior da qual foram derivadas inferências a propósito dos objetivos previstos inicialmente, a partir da teoria que embasou o trabalho.

\section{Resultados e Discussão}

\subsection{Descrição do blog do NTE-Regional e sua implantação}

O blog do NTE-Regional foi publicado em julho de 2010 e divulgado para outros NTEs e escolas da Rede Estadual e Municipal através de e-mail. Antes disso o acompanhamento e orientações às escolas eram realizados somente via e-mail do PROGETEC, telefone e visitas técnicas. Devido às múltiplas funções do NTE-Regional, houve a necessidade de criação de um grande blog que funcionasse como apoio a outros blogs das escolas, funcionando não somente como um canal de comunicação entre NTE-Escola e Escola-Escola, mas como meio de orientação e construção coletiva do conhecimento, favorecendo assim a aprendizagem e interação entre as partes, formando uma rede de aprendizagem.

Assim, o "Blog NTE-Regional" é na verdade um conjunto de vários blogs interligados por links que funcionam como um sistema hipertextual. Até o momento têm-se oito blogs interligados por um blog principal. Cada um trata de um assunto específico (Tabela 1). Todos os assuntos são postados por meio de arquivos de texto, imagem e som, com objetivos relacionados às atribuições do NTE. São classificados em três tipos: principal, que funciona como a página inicial e onde estão "linkados" um conjunto de blogs; secundários que são acessados a partir do principal e tratam de assuntos específicos e; sub-blogs que são acessados a partir dos secundários e tratam de subtemas referentes a eles. A Tabela 1 descreve individualmente os blogs que compõe o "Blog do NTE-Regional", considerando seu título, endereços e elementos que o compõe.

Tabela 1. Principais características do conjunto de blogs que compõemo "Blog NTERegional" quantoao título,endereçoe assuntotratado.

\begin{tabular}{|c|l|l|}
\hline Título & \multicolumn{1}{|c|}{ Endereço } & \multicolumn{1}{c|}{ Assunto tratado } \\
\hline NTE-Regional & nte-regional.blogspot.com & $\begin{array}{l}\text { Notícias e informações referentes a assuntos } \\
\text { gerais do NTE-Regional. }\end{array}$ \\
\hline
\end{tabular}




\begin{tabular}{|l|l|l|}
\hline Artigos & $\begin{array}{l}\text { nte-regional- } \\
\text { artigos.blogspot.com }\end{array}$ & $\begin{array}{l}\text { Artigos científicos, reportagens, livros e demais } \\
\text { tipos de publicações referentes ao uso das TDIC } \\
\text { na educação. }\end{array}$ \\
\hline Atividades & $\begin{array}{l}\text { nte-regional- } \\
\text { atividades.blogspot.com }\end{array}$ & $\begin{array}{l}\text { Atividades e projetos de sucesso realizados nas } \\
\text { escolas e endereços de sites educacionais. }\end{array}$ \\
\hline Cursos & $\begin{array}{l}\text { nte-regional- } \\
\text { cursos.blogspot.com }\end{array}$ & $\begin{array}{l}\text { Informações gerais sobre a formação continuada } \\
\text { realizada pelo NTE nas escolas. }\end{array}$ \\
\hline Documentos & $\begin{array}{l}\text { nte-regional- } \\
\text { documentos.blogspot.com }\end{array}$ & $\begin{array}{l}\text { Documentos referentes ao funcionamento e } \\
\text { atividades do NTE e gerenciamento das TDIC } \\
\text { nas escolas, com modelos para download. }\end{array}$ \\
\hline STEs & $\begin{array}{l}\text { nte-regional- } \\
\text { ste.blogspot.com }\end{array}$ & $\begin{array}{l}\text { Uso das TDIC nas Salas de Tecnologias (STEs), } \\
\text { escola e blogs da escolas. }\end{array}$ \\
\hline UCA-Total & $\begin{array}{l}\text { nte-regional- } \\
\text { uca.blogspot.com }\end{array}$ & $\begin{array}{l}\text { Implantação e implementação do Projeto UCA, } \\
\text { orientaçôes, relatos e atividades. }\end{array}$ \\
\hline Eventos & $\begin{array}{l}\text { nte-regional- } \\
\text { eventos.blogspot.com }\end{array}$ & $\begin{array}{l}\text { Eventos, cursos e projetos realizados pelos NTEs } \\
\text { e pelas escolas. }\end{array}$ \\
\hline Visitas & $\begin{array}{l}\text { nte-regional- } \\
\text { visitas.blogspot.com }\end{array}$ & $\begin{array}{l}\text { Visitas realizadas pelo NTE-Regional às escolas } \\
\text { e devolutiva por meio de relatórios. }\end{array}$ \\
\hline
\end{tabular}

Por ser um conjunto de blogs, o Blog do NTE-Regional está organizado de forma hierárquica, com o blog principal onde estão "linkados" todos os outros blogs secundários, que por sua vez apresentam links para sub-blogs, quando necessário (Figura 1). A especificidade do assunto se torna maior do principal para os sub-blogs, sendo que os blogs ligados ao principal ou secundários são subtemas daquele que hospeda os links.

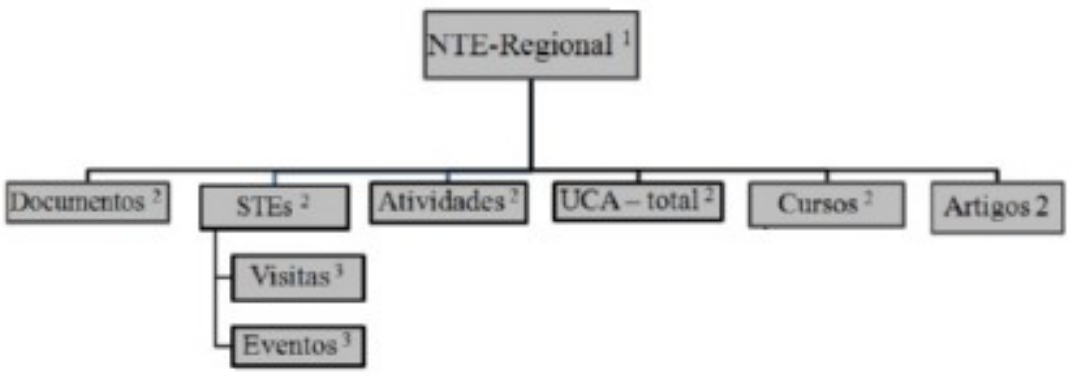

Figura 1. Esquemailustrando a hierarquia do conjunto de blogs que compõemo "Blog NTERegional"utilizandoseustítulose indicandoseé principal(1), secundário(2) ou sub-blog(3).

Embora o espaço de interação do NTE-Regional seja formado por vários blogs, foi seguido um padrão para sua construção e edição. Este desenho instrucional facilita a visualização e melhor acesso. Foram necessários o uso de outras ferramentas disponíveis na Web 2.0 para divulgação de arquivos de apresentação, textos e imagens. Assim, foi utilizado o Slide Share e Google Docs, que são serviços de compartilhamento de arquivos, por meio de contas criadas exclusivamente para esse fim Após a postagem dos arquivos nesse local, foram postados nos blogs os links para acesso direto.

\subsection{Avaliação do blog pelos usuários}

Após a implantação do blog do NTE-Regional como ferramenta de gestão, acompanhamento e orientação pedagógica, foi aplicado o questionário para investigar 
os ajustes a serem efetuados bem como a eficiência do uso da ferramenta junto aos usuários. Um total de 39 professores e gestores responderam as questões. Seguem os resultados obtidos em cada categoria analisada.

A. Design, apresentação e forma - Nessa categoria foi avaliada a organização do ambiente, a apresentação gráfica, a forma e facilidade de navegação no Blog NTERegional. Para tal, foi investigado como o blog encontra-se estruturado, a facilidade de navegação, a clareza dos links internos a partir de sua sinalização por meio de logo ou links inseridos nos textos e a facilidade de retorno à página principal a partir de qualquer blog secundário ou sub-blog.

Dos 39 questionários analisados, 44\% apontaram a estrutura e organização do blog como "ótima" e 56\% como "muito bom"; não houve respostas "ruim, razoável e péssimo". Nos itens facilidade de navegação, clareza dos links internos e facilidade de retorno à página, 97\%, 99\% e 98\% dos respondentes, respectivamente, afirmaram que esses aspectos são positivos.

A partir desses dados é possível afirmar que o design, apresentação e forma do Blog NTE-Regional são satisfatórias e facilitam a exploração. As respostas positivas são importantes, pois representam o primeiro contato dos professores e gestores com o blog, o que pode determinar a inclusão de seu uso como possibilidade de trabalho e local de interação.

B. Estética e legibilidade - A avaliação da estética e legibilidade considerou a facilidade de leitura e exploração das informações contidas no blog em relação à formatação dos textos, organização, nitidez das ilustrações e sua coordenação com outros elementos da página, como textos e vídeos, por exemplo, e a contribuição dos arquivos de áudio e vídeo para a clareza e objetividade das informações. Além de incentivar a exploração do conteúdo, esses itens são importantes por determinarem a facilidade de interpretação das informações publicadas.

Em relação à facilidade de leitura das informações contidas no blog, 97\% dos respondentes afirmaram que não há interferência negativa do formato do texto e plano de fundo na leitura das informações contidas no blog. Ainda, 92\% dos entrevistados disseram que a estética do blog incentiva a exploração do conteúdo e os arquivos de áudio e vídeo contribuem para sua clareza e objetividade. Já em relação à nitidez e coordenação das ilustrações com outros elementos da página todos os entrevistados disseram estar adequada.

Nessa categoria, a maioria das respostas positivas indica que a formatação e organização dos elementos do blog são satisfatórias, estimulando sua exploração e facilitação da navegação. Isso é importante, pois elementos como cor e formato da fonte, plano de fundo, disposição dos elementos na página, qualidade das imagens, áudio e som estão relacionados com a facilidade ou dificuldade de acesso às informações. Isso pode determinar a permanência ou não do internauta no blog.

C. Confiabilidade e objetividade - Essa categoria avaliou a objetividade e a confiança dos professores em relação ao conteúdo postado, considerando se as informações dos textos puderam ser confirmadas em outras referências, assim como, sua clareza e objetividade e se os links associados aos posts levaram às informações complementares.

Dos participantes, $89 \%$ disseram que as informações mencionadas podem ser confirmadas e $11 \%$ afirmaram que a confirmação é parcial. Embora seja a minoria, é importante investigar junto a essas pessoas quais informações não puderam ser checadas e proceder a revisão. A maioria dos entrevistados (97\%) respondeu que as informações 
são claras e objetivas e que os links remetem a outros sites e conteúdos complementares.

Segundo Moran (2009), a credibilidade do que é publicado na Web 2.0 é importante para seus usuários atestarem a confiança nas informações. Assim, a confiabilidade pode ser aumentada através da qualidade de gráficos, de textos corretos e de links que conduzam a sites que comprovem que houve pesquisa e que ofereçam sustentação para que os leitores comprovem as informações dadas.

Os resultados obtidos permitiram afirmar que as informações publicadas no blog NTE-Regional são claras e objetivas e podem ser confirmadas por outras fontes e que professores e gestores confiam no material publicado. Isso estimula sua exploração e uso das informações, atividades e documentos nas tarefas cotidianas dos participantes.

D. Interação e relação com a prática docente - Nessa categoria foi avaliada a eficiência do papel do blog na interação entre NTE-Escola e Escola-Escola e a relação com a prática docente dos professores jurisdicionados ao núcleo. Para tal, foi considerado o blog como facilitador da comunicação entre escola e NTE e a divulgação do trabalho pedagógico com uso das TDIC realizado na escola. Também, foi analisado se o acesso aos trabalhos realizados em outras escolas foi simplificado e se houve melhoria da prática pedagógica com uso do blog. Esses itens têm grande relevância por estarem ancorados nas categorias $\mathrm{A}, \mathrm{B}$ e $\mathrm{C}$ e diretamente relacionados aos objetivos da criação do blog, permitindo mensurar a eficiência do uso blog na prática.

Dos professores e gestores que responderam às questões, $66 \%$ afirmam que a comunicação entre escola e NTE melhorou com o uso do blog, 29\% afirmaram que a melhoria foi parcial - mas não satisfatória - e 5\% avaliam que não houve melhoria na comunicação. No que diz respeito à divulgação do trabalho realizado na Escola, 58\% relataram maior facilidade na divulgação, 35\%, facilidade parcial e 7\% dizem que não houve facilitação. Quanto ao blog simplificar o acesso aos trabalhos realizados em outras escolas, $76 \%$ afirmaram que houve simplificação, $20 \%$ disseram ser parcial, enquanto 4\% disseram que não simplifica. No correspondente à melhoria da prática, $71 \%$ responderam que houve melhora, $25 \%$ que a melhora foi parcial e $4 \%$ dizem que não houve melhora.

Embora as respostas negativas tenham apresentado baixos percentuais, é relevante considerar o número intermediário de respondentes. Esses resultados demonstraram que parte dos professores e gestores ainda não se habituaram a utilizar o blog como um canal de comunicação entre a escola e o núcleo, nem como um espaço de compartilhamento de experiências, debates e aprendizagem. É relevante considerar os fatores que estão impedindo a efetiva incorporação dessa ferramenta na prática pedagógica, bem como traçar ações para resolver esses problemas.

Considerar os aspectos citados como positivos pelos usuários do blog e ouvir suas sugestões para a melhoria do mesmo podem auxiliar a detectar as causas dessas respostas parciais e melhorar o uso do blog entre os docentes.

E. Aspectos positivos do uso do Blog NTE-Regional - A avaliação desses aspectos possibilita reforçar as características que influenciam positivamente o uso do blog e suas vantagens na visão de professores e gestores. A questão aberta possibilitou uma gama maior de opções e flexibilizou as respostas, permitindo a observação na totalidade e servindo de base para detectar os avanços já conquistados.

Por meio da técnica da análise de conteúdo, foram classificadas 15 categorias de análise a partir de 75 respostas obtidas. Os aspectos positivos mais citados pelos professores e gestores foram: maior interação (22\%), mais informações $(16 \%)$, melhor 
comunicação (15\%), divulgação do trabalho (14\%), mais sugestões de atividades e conteúdos (13\%), compartilhamento de experiências (9\%) e possibilidade de ampliar o uso de recursos tecnológicos (3\%). Foram citados também dentre os aspectos positivos a possibilidade de vivenciar experiências pedagógicas concretas, maior facilidade de estudos e pesquisas, a valorização profissional, a facilidade de debates com outros profissionais, a valorização profissional, auxílio na construção de blogs das escolas, maior conhecimento de possibilidades de uso dos recursos tecnológicos e autoavaliação $(11 \%)$.

Segundo Gomes e Lopes (2007) e Marques et al. (2010), uma exploração dos blogs, enquanto recurso pedagógico consiste na criação, customização e dinamização destes pelos professores, centrados na abordagem de conteúdos relacionados com a área que leciona e na dinâmica educacional. Os blogs educacionais procuram disponibilizar informações que acompanham a sequência de assuntos tratados nas aulas e referenciem notícias e acontecimentos recentes que apresentam relações com temáticas curriculares, permitindo maior interação e colaboração participativa. Além disso, as informações produzidas nesses locais podem ampliar o espaço da escola produzindo saberes essenciais na formação dos educandos [Santiago e Lima 2013].

A partir da análise dos aspectos citados é passível afirmar que o blog do NTERegional está atingindo seu propósito de interação, divulgação e compartilhamento de experiências. Essa relação é favorecida pela formação de uma rede em um ambiente que incentiva e facilita a cooperação, coordenação e o trabalho em equipe, permitindo a redefinição permanente de ações e métodos.

F. Sugestões para melhorar o Blog NTE-Regional - A partir das sugestões dos entrevistados e análise das respostas foram consideradas 15 categorias. Foram consideradas "não válidas" as respostas que não pontuavam sugestões, apenas relatavam situações, problemas e fatos ocorridos na escola com uso dos recursos tecnológicos. $\mathrm{Na}$ categoria "sem sugestão" foram consideradas as respostas em que os entrevistados afirmavam não serem necessárias modificações e/ou melhorias no blog ou que responderam diretamente não ter sugestão.

Das 44 respostas obtidas, $31 \%$ foram classificadas na categoria maior divulgação do blog na escola, $16 \%$ intensificar sugestão de sites educacionais, $14 \%$ sem sugestão e $11 \%$ não foram respostas válidas. Também, porém em menor número, foi sugerido intensificar a sugestão de sites, softwares, divulgação de notícias e publicações da área de tecnologias na educação (24\%). Foi sugerida ainda a criação de um espaço para a postagem, análise e publicação pelos professores de atividades (4\%). Isso demonstra a disposição dos professores e gestores em participar do blog e torná-lo uma ferramenta de apoio, divulgação e interação. Essas sugestões são executáveis e podem ser realizadas com a abertura de mais espaços (sub-blogs) relacionados ao blog secundário STEs. Outras sugestões podem ser atendidas com realização de mais enquetes, criação de uma comunidade virtual vinculada ao blog, disponibilização de espaço de busca, continuidade do auxílio à criação e edição do blog das escolas jurisdicionadas.

O primeiro resultado demonstrou que apenas a divulgação do blog por meio de e-mail pessoal e institucional não foi suficiente para sua propagação, sendo necessária a definição de outras estratégias de divulgação. Além do e-mail, também poderão ser utilizados documentos impressos enviados às escolas e as redes sociais. Poderão ainda ser realizadas enquetes consultando outras formas de divulgação ampliando para a comunidade interna e externa, de acordo com a realidade de cada escola. 
Recorrendo aos objetivos iniciais, vemos que a interação entre NTE-Escola e relação do uso do blog com a prática docente, através da divulgação, reflexão e experiências compartilhadas, não é totalmente satisfatória. Essa constatação está relacionada à falta de uma divulgação mais intensa e um maior número de materiais (atividades, textos, softwares e sites) pedagógicos produzidos pelos professores, bem como um incentivo maior à interação.

O alto número de respostas sem sugestão (14\%) pode ser interpretado de formas divergentes. Esse dado pode indicar que o blog está atendendo às necessidades dos professores e gestores, estando de acordo com os objetivos iniciais de sua criação. No entanto, essa inferência deve ser cautelosa, pois ao associar esse resultado com o alto número de sugestões de maior divulgação pode-se deduzir que os participantes da avaliação não conheceram o blog suficientemente e não se sentiram seguros para elencar sugestões.

Relacionando todos os resultados obtidos, é possível verificar que o design, a apresentação, a forma, estética e legibilidade do blog são satisfatórios, facilitam e estimulam sua exploração. As informações são objetivas, claras e confiáveis, mas falta maior divulgação do ambiente.

A correção dos problemas é fundamental quando se pretende utilizar o blog com função mediadora do desenvolvimento cognitivo, uma vez que a interação entre professores e gestores levará a um processo de aprendizagem social entre os pares. Nesse aspecto, é válido utilizar a observação de Vygotsky, citada por Tinzmann et al. (1990), de que professores eficientes criam e planejam juntos, utilizando o conceito de zona proximal. Reportando a essa ideia pode-se afirmar que seu uso deve valorizar o diálogo e a participação de todos os envolvidos, sendo que na sua criação, edição e revisão deve ser considerado, como citado pelo mesmo autor (ibid, 1990), a competência do aprendiz, a divisão de interesses, a intuição e a incerteza, uma vez que a partir do interesse coletivo e das interações nas postagens, o blog torna-se um ambiente efêmero.

É oportuno lembrar que para ter sucesso no uso do blog como um apoio ao trabalho do NTE-Regional é muito importante que professores e gestores se tornem membros ativos desse espaço, cabendo ao núcleo estimular e conscientizar a importância de um espaço de interação e apoio para as atividades utilizando os recursos tecnológicos e intervir com modificações no blog visando à melhoria de sua utilização e sua integração na prática pedagógica.

\section{Conclusão}

Considerando as funções do NTE-Regional nas escolas, foi necessário um local que integrasse NTE-Escola e Escola-Escola e que funcionasse como um espaço de apoio às funções do núcleo, num ambiente colaborativo e de aprendizagem em rede. Por ser uma ferramenta que estimula a interação num ambiente de motivação, discussão, criação e divulgação do conhecimento, o blog possibilitou melhoria na comunicação e maior interação entre NTE-Escolas, apresentando grande potencial para ser utilizado como recurso pedagógico e de gestão no apoio às atividades do NTE-Regional. Essa melhoria possibilitou um acompanhamento e orientação mais eficaz e compartilhada com os demais segmentos da escola e maior interação entre as escolas jurisdicionadas ao NTERegional.

Vale ressaltar que o design do blog encontra-se estruturado, com boa apresentação e facilidade de navegação, apresentando clareza dos links, permitindo uma 
hipertextualidade, conforme observado na análise categorial. O material divulgado foi confiável e objetivo, o que aumentou a credibilidade de professores e gestores, porém, a divulgação foi precária podendo ser considerada como uma variável da pesquisa.

É relevante salientar a dinamicidade e flexibilidade do uso do blog e a necessidade da participação dos professores e gestores das escolas na sua construção a fim de motivar seu uso como canal de comunicação com o NTE e outras escolas, bem como a importância de unificar a estrutura dos blogs das escolas e de outros NTEs que poderão também utilizá-lo como apoio às suas funções.

Não se teve a intenção de esgotar o tema, mas são necessários estudos futuros que analisem os blogs de outros NTEs a fim de propor a unificação de seu uso como ferramenta de apoio à melhoria da gestão e suporte desses núcleos à integração dos recursos tecnológicos à prática pedagógica.

\section{Referências bibliográficas}

Araújo, M. C. M. U. (2009). "Potencialidades do uso do blog em educação". Natal: UFRN, 2009. Dissertação de Mestrado.

Bardin, L (1997). “Análise de conteúdo”. Lisboa, Edições 70, 1977.

Gomes, M. J; Lopes, A. M. (2010). "Blogues escolares: quando, como e porquê?”, http://www.edumat.com.br, Novembro.

Levy, P. (2005). "A inteligência coletiva por uma antropologia do ciberespaço." Tradução Luiz Paulo Rouanet, 4 ed, São Paulo: Loyola, 2005.

Marques, A. de M., Pimentel, M., Siqueira, S. (2010). "Dinâmicas Educacionais com o Uso de Blogs: Requisitos a partir de Experiências." Anais do XVI WIE. Belo Horizonte. pp. 1177-1186.

Mato Grosso do Sul. (2011). Secretaria de Educação. "Resolução/SED n. 2491, de 8 de dezembro de 2011", http://ww1.imprensaoficial.ms.gov.br/, Dezembro, p. 14.

Moran, J. M. (2009). “A educação que desejamos: Novos desafios e como chegar lá. Editora Papirus, $4^{\text {a }}$ Ed.

Pontes, R. L. J. e Filho, J. A. C. (2011). "O uso do blog como ferramenta de ensinoaprendizagem por professores participantes do Projeto Um Computador por Aluno (UCA)". Anais do XVII WIE. Aracaju. pp. 1478-1487.

Prado, M. E. B. B. (2010). "Integração de mídias e a reconstrução da prática pedagógica". Material complementar. Especialização: Tecnologias em educação. Rio de Janeiro: CCEAD/PUCRio.

Santiago, M. F. C. E Lima, R. W. (2013). "Blog: Uma Ferramenta de Aprendizagem no Ensino Médio Inovador". Anais do XIX WIE. Campinas/SP, pp. 80-89.

Tinzmann, M. B. et al. (1990). "What is the collaborative classroom?" North Central Regional Educational Laboratory (NCREL), Oak Brook.

Vigotsky, L.S. (2008). "Pensamento e Linguagem.” São Paulo: Martins Fontes. 